J Int Neuropsychol Soc. 2018 September ; 24(8): 805-820. doi:10.1017/S1355617718000425.

\title{
Change in Cognitive Performance from Midlife into Old Age: Findings from the Midlife in the United States (MIDUS) Study
}

\author{
Matthew L. Hughes ${ }^{1}$, Stefan Agrigoroaei ${ }^{2}$, Minjeong Jeon ${ }^{3}$, Molly Bruzzese ${ }^{1}$, and Margie E. \\ Lachman ${ }^{1}$ \\ ${ }^{1}$ Brandeis University \\ Université catholique de Louvain \\ ${ }^{3}$ UCLA
}

\begin{abstract}
Objective-A substantial body of research has documented age-related declines in cognitive abilities among adults over 60 , yet there is much less known about changes in cognitive abilities during midlife. The goal was to examine longitudinal changes in multiple cognitive domains from early midlife through old age in a large national sample, the Midlife in the United States (MIDUS) study.
\end{abstract}

\begin{abstract}
Method-The Brief Test of Adult Cognition by Telephone (BTACT) was administered on two occasions (MIDUS 2, MIDUS 3), an average of 9 years apart. At MIDUS 3, those with the cognitive assessment $(N=2,518)$ ranged in age from 42 to 92 years $(M=64.30, S D=11.20)$ and had a mean education of 14.68 years $(S D=2.63)$. The BTACT includes assessment of key agingsensitive cognitive domains: immediate and delayed free recall, number series, category fluency, backward digit span, processing speed, and reaction time for attention switching and inhibitory control, which comprise two factors: episodic memory and executive functioning.
\end{abstract}

Results-As predicted, all cognitive subtests and factors showed very small but significant declines over 9 years, with differences in the timing and extent of change. Processing speed showed the earliest and steepest decrements. Those with higher educational attainment scored better on all tests except reaction time. Men had better executive functioning and women performed better on episodic memory.

Conclusions-Examining cognitive changes in midlife provides opportunities for early detection of cognitive impairments and possibilities for preventative interventions.

\footnotetext{
Correspondence concerning this article should be addressed to Margie E. Lachman, Department of Psychology, MS 062, Brandeis University, Waltham, MA 02453, lachman@ brandeis.edu.

Matthew L. Hughes is now at the Department of Psychology, University of North Carolina at Greensboro

Stefan Agrigoroaei, Psychological Sciences Research Institute, Université catholique de Louvain

Minjeong Jeon, Graduate School of Education \& Information Studies, University of California, Los Angeles

Molly Bruzzese, Department of Psychology, Brandeis University

Margie E. Lachman, Department of Psychology, Brandeis University

No conflicts of interest to report.

The MIDUS 3 and longitudinal change data have not been previously presented or published. Cognitive data from MIDUS 2 were published in Lachman et al. (2014).
} 


\section{Keywords}

middle aged; cognitive aging; sex differences; educational status; longitudinal studies; cognitive function

\section{Topic areas}

Elderly/Aging; Follow-up and Longitudinal Studies

Compromised cognitive functioning in later life has been identified as a risk factor for increased morbidity and mortality (Schaie, 1996; Swan, Carmelli, \& LaRue, 1995).

Although a good deal is known about cognition in old age in comparison to young adults (especially college students), much less is known about cognition in midlife (Bielak, Hughes, Small, \& Dixon, 2007; Salthouse, 2010; Soederberg Miller \& Lachman, 2000;

Sternberg, Grigorenko, \& Oh, 2001; Willis \& Boron, 2008; Willis \& Schaie, 1999; Willis \& Schaie, 2006). Further understanding of the nature of midlife cognition can provide insights into the emergence of cognitive decline (Agrigoroaei \& Lachman, 2011). The present study used data from the Midlife in the United States (MIDUS, Brim, Ryff, \& Kessler, 2004), a longitudinal study of adults across a wide age range (ages 25 to 95) from early midlife through old age, to examine changes over 9 years in multiple cognitive domains using a brief telephone battery. In addition we examined whether there are differences in change as a function of age, sex, and education.

There is a surprising paucity of national data in the United States (U.S.) on cognitive functioning across the adult lifespan, from young adulthood through mid- and later life. Many of the previous studies have specialized, clinical, or convenience samples or are based on local samples in the U.S. or Canada (e.g., Framingham Heart Study, Normative Aging Study, Seattle Longitudinal Study, Victoria Longitudinal Study) and Europe (e.g., Swedish Twin Study, Berlin Aging, Bonn Longitudinal Study). Many major epidemiological surveys such as the Longitudinal Survey on Aging (LSOA; Miller, Rejeski, Reboussin, Ten Have, \& Ettinger, 2000) do not measure cognitive function or only include a dementia screener (see Lachman \& Tun, 2008). One exception is the U.S. Health and Retirement Study (HRS), a survey of more than 20,000 adults ages 50 and above (Herzog \& Wallace, 1997; McArdle, 2011), which included a measure of immediate and delayed recall (e.g. Fisher et al., 2014). However, many of the findings from the HRS longitudinal cognitive data are derived from a limited set of items from dementia screeners that are not sensitive to differences in normal aging, especially in midlife. Recently, the HRS has expanded its cognitive battery to include more age sensitive measures such as inductive reasoning (e.g., number series) and category fluency (e.g., animal naming), domains also present in the MIDUS study (McArdle, 2011); however, the HRS study does not include adults under the age of 50. Thus, no large-scale U.S. national data sets with multiple aspects of cognition are available with younger and middle-aged men and women in their 30s and 40s, and continuing through older adulthood (Piccinin \& Hofer, 2008). 


\section{Cognitive Aging}

In the last two decades a substantial body of research has documented age-related declines in cognitive abilities among adults over 60 (e.g.,; Craik \& Salthouse, 2008; Hofer \& Alwin, 2008; Karlamangla et al., 2009; Salthouse, 1996; Schaie, 1994; Hultsch, Hertzon, \& Dixon 1990). Much of this cognitive aging literature is based on relatively small samples of college students and older adult volunteers matched for educational level and brought into university labs, whereas middle-aged adults or those without some college education are included less often (Lachman, 2015). Other cross sectional studies using volunteer samples have examined cognitive abilities across adulthood, showing the most pronounced age differences for processing-intensive abilities (e.g., speed of processing, working memory, executive function) beginning as early as the 20s. (McCabe, Roediger, McDaniel, Balota, \& Hambrick, 2010; Park et al., 2002).

There are a number of longitudinal studies, largely conducted in Europe and Australia (e.g., Whitehall in England, Betula and Twin Studies in Sweden, Interdisciplinary Study on Adult Development in Germany, and the Path Study in Australia) that have included participants under the age of 50 with a broader educational range. These studies provide evidence that there are declines in cognitive functioning as early as the mid 40s (Anstey, Sargent-Cox, Garde, Cherbuin, \& Butterworth, 2014; Brunner et al., 2017; Davis et al., 2017; Rönnlund \& Nilsson, 2006; Singh-Manoux et al., 2012; Zimprich \& Mascherek, 2010). Findings on age differences from cross-sectional, normative studies of cognitive batteries such as the Wechsler Adult Intelligence Scale (WAIS; Wechsler, 1997), are consistent with these longitudinal findings (Ryan, Sattler, \& Lopez, 2000).

In general there is consistent evidence of age-related declines in cognition, yet there are wide individual differences and variations in the timing and extent of cognitive decline. The differences arise in part due to the age range of the participants, the length of the time intervals between the occasions of measurement, as well as the particular cognitive domains studied. In summary, across key longitudinal studies of cognitive aging, the evidence shows that some domains begin to show declines earlier than others (e.g., speeded measures), and there is some variation in when cognitive change is found to begin. The current study is the first to examine longitudinal cognitive changes on a wide range of domains including adults under the age of 50 and into old age and using a telephone battery in a national sample in the U.S.

\section{Differences by Education and Sex}

In addition to age differences, there is evidence for differences in cognitive functioning by education (the most commonly used marker of socioeconomic status in cognitive aging research). Those with lower educational attainment generally show poorer cognitive functioning (Cagney \& Lauderdale, 2002; Lee, Kawachi, Berkman, \& Grodstein, 2003; Lyketsos, Chen, \& Anthony, 1999; Rabbitt, Donlan, Watson, McInnes, \& Bent, 1995; Singer, Verhaeghen, Ghisletta, Lindenberger, \& Baltes, 2003; Turrell et al., 2002), but there are inconsistent findings in relation to cognitive change (Wilson et al., 2009). Low educational attainment has been well established as a major risk factor for dementia in older 
adults (Evans et al., 1993; Ganguli et al., 1991; Hatch, Feinstein, Link, Wadsworth, \& Richards, 2007; Letenneur et al., 2000; Murden, McRae, Kaner, \& Bucknam, 1991; Uhlmann \& Larson, 1991; Wiederholt et al., 1993; Willis, 1996). However, there is mixed evidence as to whether education is associated with the timing and extent of cognitive declines in normal aging (Stern, 2002; 2009; Zahodne et al. 2011).

Sex differences have also been examined in relation to cognitive aging. Although women perform better than men on most memory tasks, men outperform women on some tests of memory especially when the test contains an analytic (Caselli et al., 2015) or spatial component (Fastenau, Denburg, \& Hufford, 1999; Gallagher \& Burke, 2007). Although there is limited evidence for differential cognitive changes by gender, some work has demonstrated a steeper decline of cognitive function for women (Karlamangla et al., 2009). Therefore, the question of whether men and women show differential trajectories of change in midlife and beyond remains of interest.

\section{Current Study}

The present study can enrich our knowledge about changes in cognitive abilities beginning early in midlife. Cognitive aging is often studied with small samples in the lab or clinic with a restricted range of education and age. The MIDUS project provides a rich opportunity to examine age differences in a more diverse national sample, using a brief battery that can be administered over the telephone, and includes measures of speed and reaction time. The availability of the MIDUS 3 longitudinal data, using the Brief Test of Adult Cognition (BTACT, Lachman, Agrigoroaei, Tun, \& Weaver, 2014), enables us for the first time to look at changes in cognition during the transitions into midlife and from midlife to old age in a large, age-heterogeneous U.S. national sample with a wide range of educational level.

As the measures included in the BTACT are markers of cognitive mechanics (fluid intelligence) rather than pragmatics or crystallized intelligence (Baltes, Lindenberger, \& Staudinger, 2006), and are sensitive to aging-related changes, we predicted that there would be significant declines on average for all cognitive measures over the 9 year period of study. We expected the declines would be consistent with the cross-sectional age differences found at MIDUS 2 (Lachman et al., 2014); that is the declines would begin by 50 years of age, the amount of the decrement would become larger with age, and would be most pronounced for measures of processing speed and the least pronounced for backwards digit span. Based on the previous cross-sectional findings, we predicted there would be sex and education differences in level, but not in the amount of change for these variables.

\section{Method}

\section{Participants}

The current study focused on the participants from the second and third waves of the MIDUS national longitudinal study who completed the cognitive assessment (the BTACT was not administered at MIDUS 1). The study was approved by the institutional review boards involved with MIDUS. The initial MIDUS 1 probability sample $(N=7,100)$ was generated in 1995-1996 through random digit dialing of U.S. households having at least one 
telephone in the contiguous 48 states, stratified by age with an oversample of those between 40 and 60 years of age. The original participants ranged in age from 24 to 75 years $(M=$ $46.40, S D=13.00$ ) with a mean education level of 13.21 years, and $51.7 \%$ women; minorities were underrepresented with Whites comprising $90.7 \%$ of the sample (for more information, see Brim, Ryff, \& Kessler, 2004). The second occasion of measurement, MIDUS 2, was nine years later, and $75 \%$ of the original sample, adjusted for mortality ( $N=$ 4,955), was retested (Radler \& Ryff, 2010). At MIDUS 2, participants ranged in age from 32 to 84 years $(M=55.36, S D=12.40)$ and had a mean education level of 14.24 years $(S D=$ 2.60). Women made up 53.8\% of the sample, and Whites were $90.1 \%$ of the sample. The mean self-rated health on a 5 -point scale $(1=$ poor, $5=$ excellent $)$ was $3.53(S D=1.02)$. As is typically found, those who participated at the second wave showed some differences on MIDUS 1 variables compared with those who dropped out of the study (Radler \& Ryff, 2010). Compared to the dropouts, longitudinal participants were more highly educated, $t(6757)=12.48, p<.001$, (Mean years of education 14.06 versus 13.21); were more likely to be women, (53.8\% versus 48.3\%), $\chi 2(1)=17.49, p<.001$; and had higher self-rated health, $t(6759)=10.42, p<.001$, (Mean $=3.61$ versus 3.33$)$. Dropouts were more likely to be non-white (16\%) compared to the longitudinal participants (7\% non-white), $\chi 2(1)=$ $112.22, p<.001$.

MIDUS 3 was conducted 9.12 years later on average $(S D=.53)$. Of the sample from MIDUS 2, 76.9\% of those eligible $(N=3,294)$ were reinterviewed. At MIDUS 3, those with the cognitive assessment $(N=2518)$ ranged in age from 42 to 92 years $(M=64.30, S D=$ $11.20)$ and had a mean education level of 14.68 years $(S D=2.63)$. Women made up $55.3 \%$ of the sample, the mean self-rated health was $3.46(S D=1.01)$, and whites made up $90.4 \%$ of the sample.

\section{Measures and Procedure}

Demographics-Age, sex, and education information was obtained in the telephone interview. Age was used as a continuous variable in analyses. Education was converted into the number of years of education.

Health-Health was assessed in the mail-back self-administered questionnaire. Participants rated their physical health (Idler \& Benyamini, 1997) on a five-point scale ranging from 1 (poor) to 5 (excellent).

The MIDUS Cognitive Battery: The Brief Test of Adult Cognition by Telephone (BTACT)-The BTACT (Lachman et al., 2014) assesses key cognitive domains that are of theoretical significance for cognitive aging, and was designed for telephone administration with a wide range of ages and levels of educational attainment (Tun \& Lachman, 2006; Lachman \& Tun, 2008). The BTACT battery includes a combination of existing and new subtests, and is a reliable, valid measure of cognition, despite its brief length (for more information, see Lachman et al., 2014). Seven cognitive tests are included in the BTACT (Lachman et al., 2014). This included two measures of episodic memory (immediate and delayed free recall of 15 words), inductive reasoning (Number Series; completing a pattern in a series of 5 numbers), category verbal fluency (the number of words produced from the 
category of animals in $60 \mathrm{~s}$ ), working memory span (backward digit span; the highest span achieved in repeating strings of digits in reverse order), processing speed (30 Second and Counting Task, or 30-SACT; the number of digits produced by counting backward from 100 in $30 \mathrm{~s}$ ), and attention switching and inhibitory control (Stop and Go Switch Task, SGST; Tun \& Lachman, 2008). For the SGST, reaction times were calculated with the mean of switch and nonswitch trials median latencies on a task requiring alternating between the "normal" condition (i.e., respond "Go" to the stimulus "Green" and "Stop" to the stimulus "Red") and the "reverse" condition (i.e., respond "Stop" to the stimulus "Green" and "Go" to the stimulus "Red").

Given the relatively high rate of cellphone use at Time 3 (25.6\% used cellphones), it was necessary to correct for the typical delay in voice transmission when compared to landlines. Immediately before and after the SGST, all participants completed a metronome task where they were asked to count in cadence with a digital metronome. A metronome was set at 1 second intervals and the participants were instructed to listen to get the beat, and then to count out loud from one to ten at the exact time as the metronome clicks sounded. The delay between the click and the moment the participant responded was measured for each participant, and a median latency value was calculated for the pre- and post-test block. The first two trials of each block were discarded as practice trials. In some cases, participants were able to match the cadence of the metronome exactly. These cases were deemed to have no delay, and were given a latency score of 0 . Once the median latency was calculated, the pre- and post-test blocks were averaged together. This average was then subtracted from the participant's raw reaction time to obtain a corrected reaction time. Only participants who used cellphones were corrected in this way.

As is typical in longitudinal studies, those who participated at the third wave showed some differences on MIDUS 2 variables compared with those who dropped out of the study (see Table 1). Compared to dropouts, longitudinal participants performed significantly better on all cognitive tests and factors at MIDUS 2 (see Table 1 for means).

\section{Data Analysis and Results}

\section{Descriptive Results}

Correlations of age, sex, education with all cognitive measures are shown in Table 2. As expected, at both occasions, better test performance was associated with younger age and higher education. Women performed better on the episodic memory subtests and factor, and men did better on the executive functioning factor and all other subtests except backward digit span.

All cognitive tests demonstrated relatively high test-retest correlations with an average of .59 and a range of .38 to .85 (see Table 3). Table 4 presents the mean scores for all tests at MIDUS 2 and MIDUS 3.

\section{Longitudinal Measurement Invariance}

Separate confirmatory factor analyses (CFA) at MIDUS 2 and MIDUS 3 were conducted and confirmed that the BTACT captures two factors, episodic memory (EM) and executive 
functioning (EF), consistent with previous literature (Lachman et al., 2014; Lachman, Agrigoroaei, Murphy, \& Tun, 2010; Farias et al., 2013; Jurado \& Rosselli, 2007; Royall et al., 2002). For longitudinal analysis, however, it is important to ensure that the same construct is being measured over time because otherwise, the changes may reflect differences in the factor structure rather than changes in the same construct (Horn \& McArdle, 1992).

To assess factorial invariance of the BTACT at two occasions (MIDUS 2, MIDUS 3), we fit a series of CFA models with increasing invariance constraints: configural invariance (same conceptual factor structure), weak invariance (same factor loading structure), strong invariance (same factor loadings and same intercepts), and strict invariance (same factor loadings, same intercepts, and same residual variances; Isiordia \& Ferrer, 2016; Vandenberg \& Lance, 2000). The CFA models were estimated using full information maximum likelihood estimation with Mplus (Muthén \& Muthén, 2008). The SGST Latency variable was multiplied by $(-1)$ so that higher scores would correspond to faster reaction times. Based on the log-likelihood tests $(p<.05)$, we found that a weak invariance model was best supported by the data $, \chi^{2}(72)=548.43, p<0.01$, Root Mean Square Error of Approximation $($ RMSEA $)=0.040$, comparative fit index $(\mathrm{CFI})=0.967$, Tucker Lewis Index $(\mathrm{TLI})=0.959$, although the more stringent models also fit reasonably well (see Table 5 and Supplementary Table S1). Factor scores were computed as the mean of the standardized test scores loading on each factor, based on the MIDUS 2 means and standard deviations for both occasions.

\section{Longitudinal Analyses for the BTACT Subtests and Factors}

We examined cognitive change over the 9 years and differences by age, sex, and education. To investigate changes in the seven subtests over time, we applied a linear mixed effects model (LME), which has also been described as a multilevel or hierarchical model (Ghisletta, Rabbitt, Lunn, \& Lindenberger, 2012; MacCallum, Kim, Malarkey, \& KiecoltGlaser, 1997). LME provides a flexible and powerful statistical modeling framework for the analysis of longitudinal data with missing observations (Fitzmaurice, Laird, \& Ware, 2011; Verbeke \& Molenberghs, 2000). All observations at MIDUS 2 and MIDUS 3 were included in these analyses.

We specified a multivariate linear mixed effects model to the seven subtests. Denote $Y_{i k t}$ be the response for subject $i(=1, \ldots, 4206)$ to subtest $k(=1, \ldots, 7)$ at time $t(=1,2)$. The multivariate linear mixed effects model for $Y_{i k t}$ was specified as follows:

$$
Y_{i k t}=\beta_{0 k}+\beta_{1 k} \text { Time } 2+u_{0 i k}+u_{1 i k} \text { Time } 2+\varepsilon_{i k t}
$$

where $\beta_{0 k}$ is the subtest specific intercept representing the mean score of the $k$-th subtest at the first occasion (MIDUS 2), and $\beta_{1 k}$ is the subtest specific slope representing the mean score change between the two occasions (MIDUS 3-MIDUS 2) in the $k$-th subtest. The subtest specific random effects for the intercept and the change, $\left(u_{0 i k}, u_{1 i k}\right)^{\prime}$ were assumed to 
follow a bivariate normal distribution $\left(u_{0 i k}, u_{1 i k}\right)^{\prime} \sim B N\left(0, \quad \sum\right)$, where $\sum$ is a $2 \times 2$ covariance matrix. The level-1 subtest specific residual $\varepsilon_{i k t}$ was assumed to follow a normal distribution, $\varepsilon_{i k t} \sim N\left(0, \quad \sigma_{k}^{2}\right)$. For computational ease, we assume homoscedasticity for the level-1 and level-2 random effects terms. We additionally considered a bivariate linear mixed effects model for the EM and EF factors. The model formulation is equivalent to Equation (1). The difference is that the subscript $k$ indicates the EM factor when $k=1$ and the EF factor when $k=2$.

We also incorporated age, sex, and education years in the model to investigate the effects of those covariates on the intercept (mean score at MIDUS 2) and the slope (mean score difference, MIDUS 3-MIDUS 2). In addition, we further examined the interactions to test whether the effects of age on the change (difference scores) would be moderated by sex and education years. Note that age and education years are continuous variables and sex is a categorical variable (that takes value 0 for male and 1 for female). Age and education years were mean-centered so that the intercepts can be interpreted as the average scores.

As the MIDUS sample includes some siblings, we tested whether including within-family dependence (by including an additional random effects term for family) would change the results. We confirmed that for this test, the estimates of the key covariates and their significance remained the same. Hence, all analysis excluded the family random effects term from the model. In addition, for all models, we conducted a sensitivity analysis by including self-reported health as a covariate. As the results did not change, we report only the results without the health covariate. The multivariate and bivariate linear mixed effects models were estimated using full information maximum likelihood estimation with the R package lme4 (Bates, Mächler, Bolker, \& Walker, 2015).

For the multivariate analysis for the seven sub-tests, we first fit Model (1) assuming a global (shared) set of regression coefficients across the seven subtests. The SGST Latency variable was multiplied by $(-1)$ so that the direction is consistent with the other subtests, i.e., high scores indicate better (faster) performance, and decreases over time would indicate slowing. The effect size measure $\delta$ indicates delta total, where total is the total of the variance components (Hedge, 2007). The $\delta$ can be interpreted similar to Cohen's $d$. The main effect for age (on the intercept) was -0.09 ( $S E=0.003,95 \%$ Confidence Interval $(\mathrm{CI})[-0.10$, $-0.09], \delta=-0.028$ ), for sex (female) was $-0.16(S E=0.07,95 \%$ CI[-0.30, -0.01$], \delta=-0.031$ ), and for education years was 0.34 ( $S E=0.01,95 \% \mathrm{CI}[0.31,0.36], \delta=0.072)$. These effects were all significant at the .01 level, but only age and education effects were significant at the .001 level. In terms of effect size $\delta$, they all indicated very small effects (Sawilowsky, 2009). For cognitive change, the effect of age was -0.03 ( $S E=0.004,95 \% \mathrm{CI}[-0.04,-0.02]$, $\delta=-0.006$ ) and was significant at the 0.001 level, with a very small effect in terms of $\delta$, while the effects of sex and education years on change were not significant. In addition, the interactions between the three covariates on change were not significant. The variance for the random intercept and slope (change) were estimated as 2.29 and 2.55, respectively. The correlation between the random intercept and slope was close to 1.00, meaning that the two 
random effect terms (intercept and change) were not differentiable in this analysis. The level-1 residual variance was estimated to be 21.83 .

For the Stop and Go Switch Task, we examined whether the results were affected by including cell phones with the corrected scores. We added telephone type (cell phone vs. landline) as a variable in our model to see if there was an effect and we examined interactions of telephone type with age, education, and sex. There are no significant differences in the effects (of age, sex, education) between landline and cell users. We examined the effects of telephone type for the reaction time tests (SGST), which is the only test that is affected by cell phone use because it relies on timing. We found there were no differences in the results. Thus, we included cell phone users in all analyses.

For the bivariate model for the EM and EF factor scores, the main effect for age (on the intercept) was -0.016 ( $\mathrm{SE}=0.002,95 \% \mathrm{CI}[-0.02,-0.01], \delta=-0.016$ ), for sex (female) was $0.13(S E=0.04,95 \% \mathrm{CI}[-0.05,0.22], \delta=0.128)$, and for education years was $0.11(S E=$ $0.01,95 \% \mathrm{CI}[0.10,0.13], \delta=0.109$ ). The effect of age on cognitive change was -0.011 ( $S E=$ $0.001,95 \% \mathrm{CI}[-0.014,-0.009], \delta=-0.011)$. These small effects were all significant at the 0.01 level. The effects of sex, education, as well as the interaction effects between the three covariates on the cognitive change were not significant. The variance for the random intercept and slope (change) were estimated as 0.25 and 0.29 , respectively and the correlation between the intercept and slope was nearly 1.00 . The residual variance was 0.55 .

Given the prediction of differential change across measures, we fit the full version of Model (1) that allows for subtest specific regression coefficients for the sub-tests and for the EM/EF factors to identify what sub-tests drove the global effects that were found from the analysis reported above. For the follow-up analyses, the variance for the random intercept and slope (change) were estimated as 2.67 and 2.85 , respectively from the multivariate analysis (of the 7 sub-tests) and 0.26 (intercept) and 0.31 (slope) for the bivariate analysis of the EM and EF factors. The correlation between the random intercept and slope was close to 1.00 from both analyses, indicating that the two random effect terms (intercept and change) were not differentiable. The level-1 residual variance was estimated to be 17.72 and 0.49 from the multivariate and bivariate analyses, respectively. The parameter estimates of the regression coefficients are presented in Table 6 . The main effect of age (on the intercept) was negative and significant at $p<0.001$ for four subtests, with the exception of backward digit span ( $p$ $<.05)$, number series ( $p<.01$ ), and SGST (not significant), as well as for both EM and EF factors, all with very small effects size $\delta$. The effect of sex was significant at the 0.001 level for three subtests, except for category fluency and the EF factor $(p<.05)$, and SGST, backward digit span, and number series were not significant. Women had higher mean scores for immediate and delayed word list recall, and the EM factor, all indicating very small effect sizes in terms of $\delta$. Men scored better on the 30-SACT backward counting, category fluency, and the EF factor The effect of education years was positive and significant at the 0.001 level for the EM and EF factors and six subtests, again in contrast to the overall model, except for the SGST (not significant). For change, the effect of age was negative and significant at $p<.001$ for 30- SACT, Category Fluency, EM and EF, at $p<.01$ for Number Series, and at $p<.05$ level for word list immediate and delayed. Although in the overall model, the effects of sex and education years on change were not significant in the 
multivariate model, for descriptive purposes we examined these effects for individual tests, and found significant effects only for category fluency, at the 0.05 and 0.01 levels, respectively; women showed less decline and those with higher education showed greater decline.

We plotted the mean score change (MIDUS 3 minus MIDUS 2) for each subtest as a function of age (at the time of MIDUS 2). A bivariate smoother Loess curve was used to fit a smooth curve of the scatter plots between the change scores for the two continuous variables and age. The results are presented in Figure S1. The plots show that there is decline for all seven subtests and two factors and the extent of decline differs somewhat across the measures (see Table 6). In Table 7 and Figure 1, we present the raw mean subtest scores at MIDUS 2 and MIDUS 3 for the longitudinal sample by age decade. We conducted a doubly multivariate repeated measures analysis to examine the effects of subtest, age (by decade), sex, education (Less than BA, BA or Higher), and time (see Table S2). The two repeated measures were subtest and time. The seven MIDUS 3 subtests were standardized using means and standard deviations from MIDUS 2. We found significant main effects of time $\left[F(1,2143)=428.52, p<.001, \eta_{\mathrm{p}}{ }^{2}=.17\right]$, age $\left[F(4,2143)=119.43, p<.001, \eta_{\mathrm{p}}{ }^{2}=.18\right]$, and education $\left[F(1,2143)=215.19, p<.001, \eta_{\mathrm{p}}^{2}=.09\right]$. We also found a significant subtest $\mathrm{X}$ age $\mathrm{X}$ time interaction, $F(24,7459.8)=1.84, p=.008, \eta_{\mathrm{p}}{ }^{2}=.005$ (see Table S2). Pairwise comparisons with Bonferroni corrections revealed that the pattern and extent of changes varies by subtest and by age (see Figure 1). For example, for the 30-SACT backward counting the decline starts as early as the $30 \mathrm{~s}\left[F(1,2143)=11.22, p=.001, \eta_{\mathrm{p}}{ }^{2}=.005\right]$. For the SGST latency, the reaction time increased steadily with age starting from the $30 \mathrm{~s}[F(1$, $\left.2143)=37.22, p<.001, \eta_{\mathrm{p}}^{2}=.02\right]$. The immediate word list recall demonstrated significant decline beginning in the $40 \mathrm{~s}\left[F(1,2143)=4.24, p=.04, \eta_{\mathrm{p}}{ }^{2}=.002\right]$. For number series $[F(1$, $\left.2143)=14.59, p<.001, \eta_{\mathrm{p}}{ }^{2}=.007\right]$, category fluency $\left[F(1,2143)=13.87, p<.001, \eta_{\mathrm{p}}{ }^{2}=\right.$. $006]$, and word list delayed $\left[F(1,2143)=5.70, p=.02, \eta_{\mathrm{p}}{ }^{2}=.003\right]$ the decline started somewhat later in the 50s. For backward digit span, the declines became significant from the 60 s to the $70 \mathrm{~s}\left[F(1,2143)=8.87, p=.003, \eta_{\mathrm{p}}^{2}=.004\right]$.

Finally, we conducted a doubly multivariate repeated measures analysis to examine the effects of factor, age, sex, education, and time (see Table S2). The two repeated measures were factor and time. The results revealed significant main effects of age $[F(4,2479)=$ $\left.168.08, p<.001, \eta_{\mathrm{p}}^{2}=.21\right]$, education $\left[F(1,2479)=219.17, p<.001, \eta_{\mathrm{p}}{ }^{2}=.08\right]$, sex $[F(1$, $\left.2479)=33.39, p<.001, \eta_{\mathrm{p}}{ }^{2}=.01\right]$, and time $\left[F(1,2479)=407.40, p<.001, \eta_{\mathrm{p}}{ }^{2}=.14\right]$, We also found several significant interactions. For the interaction of factors with age $[F(4,2479)$ $\left.=10.61, p<.001, \eta_{\mathrm{p}}{ }^{2}=.02\right]$, the pattern of age differences varied by factor. For the EM factor, pairwise comparisons demonstrated that there was no difference between the $30 \mathrm{~s}$ and the 40s, but each subsequent decade scores significant lower than the last. For the EF factor, there was significicantly lower scores for all older decades. For the factor by sex ineteraction $\left[F(1,2479)=252.46, p<.001, \eta_{\mathrm{p}}{ }^{2}=.09\right]$, females had a higher EM factor score than men, but men had a higher EF factor score compared to women. For the factor by education interaction $\left[F(1,2479)=64.45, p<.001, \eta_{\mathrm{p}}{ }^{2}=.03\right]$, more highly educated participants had higher scores on both factors. However, the difference between the two education groups was larger for the EF factor than for EM factor. For the factor by time interaction $[F(1,2479)$ $\left.=103.47, p<.001, \eta_{\mathrm{p}}{ }^{2}=.04\right]$, both factor scores declined over time, but the decline was 
more pronounced for the EF score than the EM score. Finally, for the time by age interaction $\left[F(4,2479)=33.25, p<.001, \eta_{p}^{2}=.05\right]$, decline was greater in older adults. The three-way interaction between factor, time, and age was not significant.

\section{Retest Effects}

In longitudinal analyses, the effects of retesting, a threat to internal validity, must be considered. To test for retest effects we examined differences between the MIDUS sample who had been tested twice and a sample recruited in the same manner, who had been tested only once (Refresher sample). The MIDUS Refresher sample was recruited between 2011 and 2014 to replenish the original MIDUS cohort. An additional 3,577 adults who ranged in age from 23 to 76 were recruited into the Refresher sample. As with the previous waves of MIDUS, the BTACT was administered in a separate telephone interview with a completion rate of $71.3 \%(N=2,550)$. The Refresher cognitive sample had a mean age of 52.60 ( $S D=$ $14.17)$ and a mean education of 14.99 years $(S D=2.54)$. The sample was made up of $52.2 \%$ women and had a mean self-rated health of $3.55(S D=1.07)$.

To assess retest effects, we specified a linear regression model for a pooled dataset (MIDUS 3 and MIDUS Refresher sample). We compared the mean score values of each sub-test between the refresher sample and MIDUS 3 (after controlling for education years and age differences between the samples). If there were retest effects, the MIDUS 3 sample would show higher mean scores than the refresher sample. The analysis results, however, suggest that the refresher sample showed significantly higher mean values on five sub-tests than the MIDUS 3 sample (all except SGST and backward digit span) at the .05 level. Specifically, the difference (MIDUS Refresher - MIDUS 3) was 0.31 ( $S E=0.06,95 \%$ CI [0.18, 0.43], $\left.\eta_{\mathrm{p}}{ }^{2}=0.0048\right)$ for immediate word list recall, $0.26\left(S E=0.07,95 \% \mathrm{CI}[0.11,0.40], \eta_{\mathrm{p}}{ }^{2}=\right.$ $0.0026)$ for delayed word list recall, $0.08\left(S E=0.04,95 \%\right.$ CI $\left.[0.003,0.16], \eta_{\mathrm{p}}{ }^{2}=0.0008\right)$ for number series, $0.93\left(S E=0.29,95 \%\right.$ CI [1.36, 2.50], $\left.\eta_{\mathrm{p}}{ }^{2}=0.0087\right)$ for 30-SACT backward counting, and 1.04 ( $S E=0.16,95 \%$ CI $\left.[0.73,1.36], \eta_{\mathrm{p}}{ }^{2}=0.0083\right)$ for category fluency. In terms of the effect size measure $\eta_{\mathrm{p}}{ }^{2}$, all reported differences indicated neglible effects.

\section{Discussion}

The present set of results adds to our knowledge about the nature and extent of cognitive changes during the middle and later years of adulthood using a large national U.S. sample and wide age range, with adults from the mid-thirties into the early nineties. Results indicated that some cognitive changes begin as early as the 30s and 40s, whereas other aspects begin to decline some 10 to 20 years later, in the 50s and 60s (see Figures 1 and S1). The measures of speed and reaction time showed the earliest changes, beginning in adults who aged from the 30 s to the 40 s over the 9 years. In contrast, backwards digit span did not show declines until the 60s and 70s. Immediate recall showed declines in the 40s, and reasoning, delayed word recall, and category fluency showed declines beginning in the 50s. For all of the cognitive tests, the extent of decline became steeper with age. There was evidence for a factorial invariance, and both factors declined significantly over the 9 years, and the decline (cognitive change) was significantly larger at later ages for both episodic 
memory and executive functioning factors. Although the amount of change was significant, the effects sizes were very small to trival, suggesting there are substantial individual differences within age groups in the direction and extent of change. The very small effect sizes highlight the need to be cautious in interpreting the practical implications of the declines.

Differences were also found by education and sex. Consistent with past work, those with greater educational attainment had higher levels of cognitive performance across measures. There has been inconsistent evidence regarding the degree of change in relation to education. In some studies it has been suggested that there are only differences in level of performance, and the slopes do not differ by education in normal cognitive aging (Stern, 2002; 2009 Tucker \& Stern, 2011; Zahodne et al., 2011). A recent review of 10 studies found little evidence that education moderates the rate of age-related cognitive decline (Lenehan, Summers, Saunders, Summers \& Vickers, 2015), although some have found those with greater cognitive reserve (e.g., higher education) show steeper decline in later life for verbal memory (Alley, Suthers, \& Crimmins, 2007) and faster progression of decrements among those with dementia including Alzheimer's disease (Scarmeas, Albert, Manly, \& Stern, 2006; Stern, 2012). In the current study we found education was significantly related to performance on all subtests and factors except for SGST reaction time, although only related to change for one subtest. Those with higher levels of education showed steeper decline in category verbal fluency, but this results may be spurious given that the multivariate effect was not significant.

Sex differences were consistent with previous research (Jorm, Antsey, Christensen, \& Rodgers, 2004; Caselli et al., 2015). Women did better on episodic memory tasks immediate and delayed word list recall - while men did better on executive functioning, and the category fluency and speed tasks. The sex differences were generally consistent over time and across age decades, except that women showed less decline on category fluency than men did. Given that this was an exploratory analysis and the multivariate effect was not significant, the results should be interpreted conservatively.

Recent work has demonstrated that sex differences in episodic memory are attenuated for women after menopause (Rentz et al., 2017). Whereas pre- and peri-menopausal women outperformed men on all memory measures, post-menopausal women no longer showed an advantage relative to men on memory (Rentz et al., 2017). In the current study, women maintained higher performance than men on episodic memory across the age decades. However, in future work it will be important to consider whether menopausal status plays a role in memory for women, as suggested by the Study of Women Across the Nation (Karlamangla, Lachman, Han, Huang, \& Greendale, 2017).

Our comparison of the longitudinal and the refresher samples provided a way to examine retest effects (Gross et al., 2015)). The results suggest there were no significant retest effects, consistent with other studies with intervals greater than seven years (Salthouse, Schroeder, \& Ferrer, 2004). Indeed, our results are more consistent with cohort differences than with retest effects. Ideally in the future, however, we would test for retest effects with two samples from the same cohorts who were tested at the same point in time.

J Int Neuropsychol Soc. Author manuscript; available in PMC 2018 October 04. 


\section{Importance of Cognitive Functioning}

Effective cognitive function through adulthood is a key element not only in quality of life, but also in the ability to maintain independence (Royall, Palmer, Chiodo, \& Polk, 2005). Cognitive functioning has been linked to health in later life, yet this relationship has rarely been explored for young adulthood and middle age. In older adults, cognitive functioning has been associated with morbidity and mortality (Bruce, Hoff, Jacobs, \& Leaf, 1995; Swan et al., 1995); lung function (Cook et al., 1995); cardiovascular disease (Elias, Elias, Robbins, Wolf, \& D'Agostino, 2000; Karlamangla et al., 2005); sensory/motor functioning (Lindenberger \& Baltes, 1994; Wingfield, Tun, \& McCoy, 2005); diabetes (Stewart \& Liolitsa, 1999; Wu et al., 2008; Yeung, Fischer, \& Dixon, 2009); stress and allostatic load (Seeman, McEwen, Singer, Albert, \& Rowe, 1997); and functional ability (Greiner, Snowdon, \& Schmitt, 1996; Moritz, Kasl, \& Berkman, 1995). It is important to examine cognitive functioning in midlife during the early stages of disease processes. This can provide opportunities for early detection of cognitive impairments with possibilities for preventative interventions. Results using the BTACT are consistent with findings using longer batteries with multiple indicators and administered in person. The results may be useful for those interested in using a brief telephone measure to compare clinical samples with this large normative sample. For example the BTACT has been adopted in several studies of traumatic brain injury and chronic traumatic encephalopathy (e.g., Alosco et al., 2017; Dams-O'Connor et al., 2017).

\section{Limitations}

The use of cell phones for the cognitive interview became more prevalent by MIDUS 3. This poses some issues for the SGST reaction time task given that cell phone transmission of responses is generally slower than on landline phones. The transmission rate varies as a function of the cell phone carrier, distance from cell towers, and time of day due to differential usage. The metronome task we developed to address and correct for this delay has some limitations. For example, although the counting responses are expected to reflect the lag in cell phone transmission, to some extent it may also reflect individual differences in the ability to keep the beat rhythm. Nevertheless, when we examined the effects of telephone type, the results for cell phones with the corrected scores did not differ from the landline phone results.

The MIDUS sample, although originally drawn as a random, representative sample of adults in the United States, is now positively selected due to attrition. Moreover, the sample is not representative of the US in terms of minority representation. Although we have characterized the longitudinal sample in terms of how they differ from the dropouts in term of demographic and cognitive variables, it is the case that the findings may have underestimated the nature of aging-related cognitive changes. Given that those who remain in the longitudinal sample after 20 years are better educated, healthier and have better cognitive functioning, this limits the generalizability of the findings. Although our analyses did not find evidence for retest effects, given that the longitudinal sample was tested twice, there is the possibility that retest effects are operating to inflate scores. The factor structure for the BTACT was invariant over time, and the best fit was found for weak invariance 
involving only the number of factors and factor loadings. The more restricted models, however, also were acceptable, although they did not fit the data as well.

It should also be noted that given the MIDUS study sampling strategy, there were more participants in the 40 to 60 range than in the 30 s or over 70 . Such variation in sample size could affect the homegeniety of variance. However, as all age groups were sufficiently powered, and the statistical analyses tend to be robust to the influence of unequal sample sizes, this is unlikely to have affected the overall pattern of results.

Another limitation of the study is that, in the absence of brain imaging data, it is unclear to what extent the behavioral declines are reflective of brain pathology, cognitive impairment, or diseases associated with normal aging. As the sample now includes a substantial number who are over the age of 65, the MIDUS investigators are exploring ways to address this issue in the future by harmonizing with other studies with similar test batteries and dementia assessments (e.g., HRS) and by including dementia screeners to provide more information about cognitive status.

\section{Future Directions}

Given the rich set of biopsychosocial variables available in the MIDUS data set, we can articulate and test a large set of conditions and lifestyles that may put adults at risk for cognitive decline (Agrigoroaei \& Lachman, 2011). Moreover, we will be able to examine patterns of resilience and protective factors in terms of cognitive and physical health. The present analysis of differential change trajectories over a 9-year period sets the stage for future work that will examine individual differences, that is, why some people fare better than others in their cognitive functioning throughout adulthood.

\section{Supplementary Material}

Refer to Web version on PubMed Central for supplementary material.

\section{Acknowledgments}

This research was supported by grants the National Institute on Aging grants AG PO1 20166, U19 AG051426, and T32AG000204.

This research was approved by the MIDUS Investigators' Institutional Review Boards.

\section{References}

Agrigoroaei S, Lachman ME. Cognitive functioning in midlife and old age: Combined effects of psychosocial and behavioral factors. Journals of Gerontology, Series B: Psychological Sciences and Social Sciences. 2011; 66B:i130-i140. DOI: 10.1093/geronb/gbr017

Alley D, Suthers K, Crimmins E. Education and cognitive decline in older Americans results from the AHEAD sample. Research on Aging. 2007; 29:73-94. DOI: 10.1177/0164027506294245 [PubMed: 19830260]

Alosco ML, Kasimis AB, Stamm JM, Chua AS, Baugh CM, Daneshvar DH, Au R. Age of first exposure to American football and long-term neuropsychiatric and cognitive outcomes. Translational Psychiatry. 2017; 7:e1236.doi: 10.1038/tp.2017.197 [PubMed: 28926003] 
Anstey KJ, Sargent-Cox K, Garde E, Cherbuin N, Butterworth P. Cognitive development over 8 years in midlife and its association with cardiovascular risk factors. Neuropsychology. 2014; 28:653-655. DOI: 10.1037/neu0000044 [PubMed: 24635711]

Baltes PB, Lindenberger U, Staudinger UM. Life span theory in developmental psychology. In: Damon W, Lerner RM, editorsHandbook of child psychology, Vol I, Theoretical models of human development. 6th. New York: Wiley; 2006. 569-664.

Bates D, Mächler M, Bolker B, Walker S. Fitting linear mixed-effects models using lme4. Journal of Statistical Software. 2015; 67:1-48. DOI: 10.18637/jss.v067.i01

Bielak AAM, Hughes TF, Small BJ, Dixon RA. It's never too late to engage in lifestyle activities: Significant concurrent but not change relationships between lifestyle activities and cognitive speed. Journals of Gerontology, Series B: Psychological Sciences and Social Sciences. 2007; 62B:P331P339. DOI: 10.1093/geronb/62.6.P331

Brim OG, Ryff CD, Kessler RC. The MIDUS National Survey: An Overview. In: Brim OG, Ryff CD, Kessler RC, editorsHow healthy are we?: A national study of well-being at midlife. Chicago, IL, US: University of Chicago Press; 2004. 1-34.

Bruce ML, Hoff RA, Jacobs SC, Leaf PJ. The effects of cognitive impairment on 9-year mortality in a community sample. Journals of Gerontology, Series B: Psychological Sciences and Social Sciences. 1995; 50B:P289-P296. DOI: 10.1093/geronb/50B.6.P289

Brunner EJ, Welch CA, Shipley MJ, Ahmadi-Abhari S, Singh-Manoux A, Kivimäki M. Midlife risk factors for impaired physical and cognitive functioning at older ages: A cohort study. Journals of Gerontology Series A: Biomedical Sciences and Medical Sciences. 2016; 72:237-242. DOI: 10.1093/gerona/glw092

Cagney KA, Lauderdale DS. Education, wealth, and cognitive function in later life. Journals of Gerontology, Series B: Psychological Sciences and Social Sciences. 2002; 57B:P163-P172. DOI: 10.1093/geronb/57.2.P163

Caselli RJ, Dueck AC, Locke DE, Baxter LC, Woodruff BK, Geda YE. Sex-based memory advantages and cognitive aging: A challenge to the cognitive reserve construct? Journal of the International Neuropsychological Society. 2015; 21:95-104. DOI: 10.1017/S1355617715000016 [PubMed: 25665170]

Cook NR, Albert MS, Berkman LF, Blazer D, Taylor JO, Hennekens CH. Interrelationships of peak expiratory flow rate with physical and cognitive function in the elderly: MacArthur Foundation studies of aging. Journals of Gerontology, Series A: Biological Sciences and Medical Sciences. 1995; 50A:M317-M323. DOI: 10.1093/gerona/50A.6.M317

Craik FIM, Salthouse TA, editorsThe handbook of aging and cognition. 3rd. Mahwah, NJ: Lawrence Erlbaum Associates; 2008.

Dams-O'Connor K, Sy KT, Landau A, Bodien Y, Dikmen S, Felix ER, Whiteneck G. The feasibility of telephone-administered cognitive testing in individuals 1 and 2 years after inpatient rehabilitation for traumatic brain injury. Journal of Neurotrauma. (in press).

Davis D, Bendayan R, Terrera GM, Hardy R, Richards M, Kuh D. Decline in search speed and verbal memory over 26 years of midlife in a British birth cohort. Neuroepidemiology. 2017; 49:121-128. DOI: 10.1159/000481136 [PubMed: 29145205]

Elias MR, Elias PK, Robbins MA, Wolf PA, D’Agostino RB. Cardiovascular risk factors and cognitive functioning: An epidemiological perspective. In: Waldstein SR, Elias MF, editorsNeuropsychology of cardiovascular disease. Mahwah, NJ: Lawrence Erlbaum Associates; 2000.

Evans DA, Beckett LA, Albert MS, Herbert LE, Scherr PA, Funkenstein HH, Taylor JO. Level of education and change in cognitive function in a community population of older persons. Annals of Epidemiology. 1993; 3:71-77. DOI: 10.1016/1047-2797(93)90012-S [PubMed: 8287159]

Farias ST, Park LK, Harvey DJ, Simon C, Reed BR, Carmichael O, Mungas D. Everyday cognition in older adults: Associations with neuropsychological performance and structural brain imaging. Journal of the International Neuropsychological Society. 2013; 19:430-441. DOI: 10.1017/ S135561771200160 [PubMed: 23369894]

Fastenau PS, Denburg NL, Hufford BJ. Adult norms for the Rey-Osterrieth Complex Figure Test and for supplemental recognition and matching trials from the Extended Complex Figure Test. The 
Clinical Neuropsychologist. 1999; 13:30-47. DOI: 10.1076/clin.13.1.30.1976 [PubMed: 10937646]

Fisher GG, Stachowski A, Infurna FJ, Faul JD, Grosch J, Tetrick LE. Mental work demands, retirement, and longitudinal trajectories of cognitive functioning. Journal of Occupational Health Psychology. 2014; 19:231-242. DOI: 10.1037/a0035724. [PubMed: 24635733]

Fitzmaurice GM, Laird NM, Ware JH. Applied longitudinal analysis. Hoboken, NJ: Wiley; 2011.

Gallagher C, Burke T. Age, gender and IQ effects on the Rey-Osterrieth Complex Figure Test. British Journal of Clinical Psychology. 2007; 46:35-45. DOI: 10.1348/014466506X106047 [PubMed: 17472200]

Ganguli M, Ratcliff G, Huff FJ, Belle S, Kancel MJ, Fischer L, Kuller LH. Effects of age, gender, and education on cognitive tests in a rural elderly community sample: Norms from the Monongahela Valley Independent Elders Survey. Neuroepidemiology. 1991; 10:42-52. DOI: 10.1159/000110246 [PubMed: 2062416]

Ghisletta P, Rabbitt P, Lunn M, Lindenberger U. Two thirds of the age-based changes in fluid and crystallized intelligence, perceptual speed, and memory in adulthood are shared. Intelligence. 2012; 40:260-268. DOI: 10.1016/j.intell.2012.02.008

Greiner PA, Snowdon DA, Schmitt FA. The loss of independence in activities of daily living: The role of low normal cognitive function in elderly nuns. American Journal of Public Health. 1996; 86:6266. DOI: 10.2105/AJPH.86.1.62 [PubMed: 8561244]

Gross AL, Benitez A, Shih R, Bangen KJ, Glymour MMM, Sachs B, Manly JJ. Predictors of retest effects in a longitudinal study of cognitive aging in a diverse community-based sample. Journal of the International Neuropsychological Society. 2015; 21:506-518. DOI: 10.1017/ S1355617715000508 [PubMed: 26527240]

Hatch SL, Feinstein L, Link BG, Wadsworth MEJ, Richards M. The continuing benefits of education: Adult education and midlife cognitive ability in the British 1946 birth cohort. Journals of Gerontology, Series B: Psychological Sciences and Social Sciences. 2007; 62:S404-S414. DOI: 10.1093/geronb/62.6.S404

Hedges LV. Effect sizes in cluster-randomized designs. Journal of Educational and Behavioral Statistics. 2007; 32:341-370. DOI: 10.3102/1076998606298043

Herzog AR, Wallace RB. Measures of cognitive functioning in the AHEAD study. Journals of Gerontology, Series B: Psychological Sciences and Social Sciences. 1997; 52B:37-48. Special Issue. DOI: 10.1093/geronb/52B.Special_Issue.37

Hofer S, Alwin D, editorsHandbook on cognitive aging: Interdisciplinary perspectives. Thousand Oaks, CA: Sage Publishers; 2008.

Horn JL, McArdle JJ. A practical and theoretical guide to measurement invariance in aging research. Experimental Aging Research. 1992; 18:117-144. DOI: 10.1080/03610739208253916 [PubMed: 1459160]

Hultsch DF, Hertzog C, Dixon RA. Ability correlates of memory performance in adulthood and aging. Psychology and Aging. 1990; 5:356-368. DOI: 10.1037/0882-7974.5.3.356 [PubMed: 2242240]

Idler EL, Benyamini Y. Self-rated health and mortality: A review of twenty-seven community studies. Journal of Health and Social Behavior. 1997; 38:21-37. [PubMed: 9097506]

Isiordia M, Ferrer E. Curve of factors model: A latent growth modeling approach for educational research. Educational and Psychological Measurement. 2016; doi: 10.1177/0013164416677143

Jorm AF, Anstey KJ, Christensen H, Rodgers B. Gender differences in cognitive abilities: The mediating role of health state and health habits. Intelligence. 2004; 32:7-23. DOI: 10.1016/j.intell. 2003.08.001

Jurado MB, Rosselli M. The elusive nature of executive functions: A review of our current understanding. Neuropsychology Review. 2007; 17:213-233. DOI: 10.1007/s11065-007-9040-Z [PubMed: 17786559]

Karlamangla AS, Lachman ME, Han WJ, Huang MH, Greendale GA. Evidence for cognitive aging in midlife women: Study of women's health across the nation. PLoS ONE. 2017; 12:e0169008.doi: 10.1371/journal.pone.0169008 [PubMed: 28045986]

Karlamangla AS, Miller-Martinez D, Aneshensel CS, Seeman TE, Wight RG, Chodosh J. Trajectories of cognitive function in late life in the United States: Demographic and socioeconomic predictors. 
American Journal of Epidemiology. 2009; 170:331-342. DOI: 10.1093/aje/kwp154 [PubMed: 19605514]

Karlamangla AS, Singer BS, Williams DR, Schwartz JE, Matthews KA, Kiefe CI, Seeman TE. Impact of socioeconomic status on longitudinal accumulation of cardiovascular risk in young adults: The CARDIA Study. Social Science and Medicine. 2005; 60:999-1015. DOI: 10.1016/j.socscimed. 2004.06.056 [PubMed: 15589670]

Lachman ME. Mind the gap in the middle: A call to study midlife. Research in Human Development. 2015; 12:327-334. DOI: 10.1080/15427609.2015.1068048 [PubMed: 26848288]

Lachman ME, Agrigoroaei S, Murphy C, Tun PA. Frequent cognitive activity compensates for education differences in episodic memory. American Journal of Geriatric Psychiatry. 2010; 18:410. DOI: 10.1097/JGP.0b013e3181ab8b62 [PubMed: 20094014]

Lachman ME, Tun PA. Cognitive testing in large-scale surveys: Assessment by telephone. In: Hofer S, Alwin D, editorsHandbook on cognitive aging: Interdisciplinary perspectives. Thousand Oaks, CA: Sage Publishers; 2008. 506-522.

Lachman ME, Agrigoroaei S, Tun PA, Weaver SL. Monitoring cognitive functioning: Psychometric properties of the Brief Test of Adult Cognition by Telephone. Assessment. 2014; 21:404-417. DOI: 10.1177/1073191113508807 [PubMed: 24322011]

Lee S, Kawachi I, Berkman LF, Grodstein F. Education, other socioeconomic indicators, and cognitive function. American Journal of Epidemiology. 2003; 157:712-720. DOI: 10.1093/aje/kwg042 [PubMed: 12697575]

Lenehan ME, Summers MJ, Saunders NL, Summers JJ, Vickers JC. Relationship between education and age-related cognitive decline: A review of recent research. Psychogeriatrics. 2015; 15:154162. DOI: 10.1111/psyg.12083 [PubMed: 25516261]

Letenneur L, Launer LJ, Andersen K, Dewey ME, Ott A, Copeland JR, Hofman A. Education and the risk for Alzheimer's Disease: Sex makes a difference. American Journal of Epidemiology. 2000; 151:1064-1071. DOI: 10.1093/oxfordjournals.aje.a010149 [PubMed: 10873130]

Lindenberger U, Baltes PB. Sensory functioning and intelligence in old age: A strong connection. Psychology and Aging. 1994; 9:339-355. DOI: 10.1037/0882-7974.9.3.339 [PubMed: 7999320]

Lyketsos CG, Chen L, Anthony JC. Cognitive decline in adulthood: An 11.5 year follow-up of the Baltimore Epidemiological Catchment Area Study. American Journal of Psychiatry. 1999; 156:5865. DOI: 10.1176/ajp.156.1.58 [PubMed: 9892298]

MacCallum RC, Kim C, Malarkey WB, Kiecolt-Glaser JK. Studying multivariate change using multilevel models and latent curve models. Multivariate Behavioral Research. 1997; 32:215-253. DOI: 10.1207/s15327906mbr3203_1 [PubMed: 26761610]

McArdle JJ. Longitudinal dynamic analyses of cognition in the Health and Retirement Study panel. Advances in Statistical Analysis. 2011; 95:453-480. DOI: 10.1007/s10182-011-0168-z [PubMed: 25598848]

McCabe DP, Roediger HL III, McDaniel MA, Balota DA, Hambrick DZ. The relationship between working memory capacity and executive functioning: evidence for a common executive attention construct. Neuropsychology. 2010; 24:222-243. DOI: 10.1037/a0017619. [PubMed: 20230116]

Miller ME, Rejeski WJ, Reboussin BA, Ten Have TR, Ettinger WH. Physical activity, functional limitations, and disability in older adults. Journal of the American Geriatrics Society. 2000; 48:1264-1272. DOI: 10.1111/j.1532-5415.2000.tb02600.x [PubMed: 11037014]

Moritz DJ, Kasl SV, Berkman LF. Cognitive functioning and the incidence of limitations in activities of daily living in an elderly community sample. American Journal of Epidemiology. 1995; 141:4149. DOI: 10.1093/oxfordjournals.aje.a117344 [PubMed: 7801965]

Murden RA, McRae RD, Kaner S, Bucknam ME. Mini-Mental State Exam scores vary with education in blacks and whites. Journal of American Geriatrics Society. 1991; 39:149-155. DOI: 10.1111/j. 1532-5415.1991.tb01617.x

Muthén LK, Muthén BO. Mplus (Version 5.1). Los Angeles, CA: Muthén \& Muthén; 2008.

Park DC, Lautenschlager G, Hedden T, Davidson NS, Smith AD, Smith PK. Models of visuospatial and verbal memory across the adult life span. Psychology and Aging. 2002; 17:299-320. DOI: 10.1037//0882-7974.17.2.299 [PubMed: 12061414] 
Piccinin A, Hofer SM. Integrative analysis of longitudinal studies on aging: Collaborative research networks, meta-analysis, and optimizing future studies. In: Hofer S, Alwin D, editorsHandbook on cognitive aging: Interdisciplinary perspectives. Thousand Oaks, CA: Sage Publishers; 2008. 446476.

Rabbitt P, Donlan C, Watson P, McInnes L, Bent N. Unique and interactive effects of depression, age, socioeconomic advantage, and gender on cognitive performance of normal healthy older people. Psychology and Aging. 1995; 10:307-313. DOI: 10.1037/0882-7974.10.3.307 [PubMed: 8527052]

Radler BT, Ryff CD. Who participates? Accounting for longitudinal retention in the MIDUS national study of health and well-being. Journal of Aging and Health. 2010; 22:307-331. DOI: 10.1177/0898264309358617 [PubMed: 20103686]

Rentz DM, Weiss BK, Jacobs EG, Cherkerzian S, Klibanski A, Remington A, Goldstein JM. Sex differences in episodic memory in early midlife: Impact of reproductive aging. Menopause. 2017; 24:400-408. DOI: 10.1097/GME.0000000000000771 [PubMed: 27824681]

Rönnlund M, Nilsson LG. Adult life-span patterns in WAIS-R Block Design performance: Crosssectional versus longitudinal age gradients and relations to demographic factors. Intelligence. 2006; 34:63-78. DOI: 10.1016/j.intell.2005.06.004

Royall DR, Lauterbach EC, Cummings JL, Reeve A, Rummans TA, Kaufer DI, Coffey CE. Executive control function: A review of its promise and challenges for clinical research. A report from the Committee on Research of the American Neuropsychiatric Association. The Journal of Neuropsychiatry and Clinical Neurosciences. 2002; 14:377-405. DOI: 10.1176/jnp.14.4.377 [PubMed: 12426407]

Royall DR, Palmer R, Chiodo LK, Polk MJ. Normal rates of cognitive change in successful aging: The freedom house study. Journal of the International Neuropsychological Society. 2005; 11:899-909. DOI: 10.1017/S135561770505109X [PubMed: 16519269]

Ryan JJ, Sattler JM, Lopez SJ. Age effects on Wechsler adult intelligence scale-III subtests. Archives of Clinical Neuropsychology. 2000; 15:311-317. DOI: 10.1016/S0887-6177(99)00019-0 [PubMed: 14590227]

Salthouse TA. The processing-speed theory of adult age differences in cognition. Psychological Review. 1996; 103:403-428. DOI: 10.1037/0033-295X.103.3.403 [PubMed: 8759042]

Salthouse TA. Selective review of cognitive aging. Journal of the International Neuropsychological Society. 2010; 16:754-760. DOI: 10.1017/S1355617710000706 [PubMed: 20673381]

Salthouse TA, Schroeder DH, Ferrer E. Estimating retest effects in longitudinal assessments of cognitive functioning in adults between 18 and 60 years of age. Developmental Psychology. 2004; 40:813-822. DOI: 10.1037/0012-1649.40.5.813 [PubMed: 15355168]

Sawilowsky SS. New effect size rules of thumb. Journal of Modern Applied Statistical Methods. 2009; 8:597-599.

Scarmeas N, Albert SM, Manly JJ, Stern Y. Education and rates of cognitive decline in incident Alzheimer's disease. Journal of Neurology, Neurosurgery \& Psychiatry. 2006; 77:308-316. DOI: 10.1136/jnnp.2005.072306

Schaie KW. The course of adult intellectual development. American Psychologist. 1994; 49:304-313. DOI: 10.1037/0003-066X.49.4.304 [PubMed: 8203802]

Schaie KW. Intellectual development in adulthood: The Seattle Longitudinal Study. New York: Cambridge University Press; 1996.

Seeman TE, McEwen BS, Singer BH, Albert MS, Rowe JW. Increase in urinary cortisol excretion and memory declines: MacArthur studies of successful aging. Journal of Clinical Endocrinology and Metabolism. 1997; 82:2458-2465. DOI: 10.1210/jcem.82.8.4173 [PubMed: 9253318]

Singer T, Verhaeghen P, Ghisletta P, Lindenberger U, Baltes PB. The fate of cognition in very old age: Six-year longitudinal findings in the Berlin Aging Study (BASE). Psychology and Aging. 2003; 18:318-331. DOI: 10.1037/0882-7974.18.2.318 [PubMed: 12825779]

Singh-Manoux A, Kivimaki M, Glymour MM, Elbaz A, Berr C, Ebmeier KP, Dugravot A. Timing of onset of cognitive decline: results from Whitehall II prospective cohort study. BMJ: British Medical Journal. 2012; 344:d7622.doi: 10.1136/bmj.d7622 [PubMed: 22223828]

J Int Neuropsychol Soc. Author manuscript; available in PMC 2018 October 04. 
Soederberg Miller LM, Lachman ME. Cognitive performance and the role of control beliefs in midlife. Aging, Neuropsychology, and Cognition. 2000; 7:69-85. DOI: 10.1076/1382-5585(200006)7:2;1U;FT069

Stern Y. What is cognitive reserve? Theory and research application of the reserve concept. Journal of the International Neuropsychological Society. 2002; 8:448-460. DOI: 10.1017/ S1355617702813248 [PubMed: 11939702]

Stern Y. Cognitive reserve. Neuropsychologia. 2009; 47:2015-2028. DOI: 10.1016/ j.neuropsychologia.2009.03.004 [PubMed: 19467352]

Stern Y. Cognitive reserve in ageing and Alzheimer's disease. Lancet Neurology. 2012; 11:1006-1012. [PubMed: 23079557]

Sternberg RJ, Grigorenko H, Oh S. The development of intelligence at midlife. In: Lachman ME, editorHandbook of midlife development. New York: John Wiley \& Sons; 2001. 217-247.

Stewart R, Liolitsa D. Type 2 diabetes mellitus, cognitive impairment and dementia. Diabetic Medicine. 1999; 16:93-112. DOI: 10.1046/j.1464-5491.1999.00027.x [PubMed: 10229302]

Swan GE, Carmelli D, LaRue A. Performance on the digit-symbol substitution test and 5-year mortality in the Western Collaborative Group Study. American Journal of Epidemiology. 1995; 141:32-40. DOI: 10.1093/oxfordjournals.aje.a117342 [PubMed: 7801963]

Tucker AM, Stern Y. Cognitive reserve in aging. Current Alzheimer Research. 2011; 8:354-360. DOI: 10.2174/156720511795745320 [PubMed: 21222591]

Tun PA, Lachman ME. Telephone assessment of cognitive function in adulthood: The Brief Test of Adult Cognition by Telephone (BTACT). Age and Ageing. 2006; 35:629-632. DOI: 10.1093/ ageing/afl095 [PubMed: 16943264]

Tun PA, Lachman ME. Age differences in reaction time in a national telephone sample of adults: Task complexity, education, and gender matter. Developmental Psychology. 2008; 44:1421-1429. DOI: 10.1037/a0012845 [PubMed: 18793073]

Turrell G, Lynch JW, Kaplan GA, Everson SA, Helkala EL, Kauhanen J, Salonen JT. Socioeconomic position across the lifecourse and cognitive function in late middle age. The Journals of Gerontology Series B: Psychological Sciences and Social Sciences. 2002; 57:S43-S51. DOI: 10.1093/geronb/57.1.S43

Uhlmann RF, Larson EB. Effect of education on the Mini-Mental State Examination as a screening test for dementia. Journal of American Geriatrics Society. 1991; 39:876-880. DOI: 10.1111/j. 1532-5415.1991.tb04454.x

Vandenberg RJ, Lance CE. A review and synthesis of the measurement invariance literature: Suggestions, practices, and recommendations for organizational research. Organizational Research Methods. 2000; 2:4-69. DOI: 10.1177/109442810031002

Verbeke G, Molenberghs G. Linear mixed models for longitudinal data. N.Y.: Springer; 2000.

Wechsler D. Wechsler Adult Intelligence Scale-III (WAIS-III) manual. New York, NY: The Psychological Corporation; 1997.

Wiederholt WC, Chan D, Butters NM, Salmon DP, Kritz-Silverstein D, Barrett-Connor E. Effects of age, gender, and education on selected neuropsychological tests in an elderly community cohort. Journal of the American Geriatrics Society. 1993; 41:639-647. DOI: 10.1111/j. 1532-5415.1993.tb06738.x [PubMed: 8505462]

Willis SL. Assessing everyday competence in the cognitively challenged elderly. In: Smyer MA, Schaie KW, Kapp MB, editorsOlder adults' decision making and the law. New York: Springer; 1996. 87-127.

Willis SL, Boron JB. Midlife cognition: The association with personality and cognition and risk of cognitive impairment. In: Hofer S, Alwin D, editorsHandbook of aging and cognition. Thousand Oaks, CA: Sage; 2008. 647-660.

Willis SL, Schaie KW. Intellectual functioning in midlife. In: Willis SL, Reid JD, editorsLife in the middle. San Diego, CA: Academic Press; 1999. 233-247.

Willis SL, Schaie KW. Cognitive functioning in the baby boomers: Longitudinal and cohort effects. In: Whitbourne SK, Willis SL, editorsThe baby boomers grow up. Mahwah, NJ: Lawrence Erlbaum Associates; 2006. 205-234. 
Wilson RS, Hebert LE, Scherr PA, Barnes LL, De Leon CM, Evans DA. Educational attainment and cognitive decline in old age. Neurology. 2009; 72:460-465. DOI: 10.1212/01.wnl. 0000341782.71418.6c [PubMed: 19188578]

Wingfield A, Tun PA, McCoy SL. Hearing loss in adulthood: What it is and how it interacts with cognitive performance. Current Directions in Psychological Science. 2005; 14:144-148. DOI: 10.1111/j.0963-7214.2005.00356.x

Wu W, Brickman AM, Luchsinger J, Ferrazzano P, Pichiule P, Yoshita M, Small SA. The brain in the age of old: The hippocampal formation is targeted differentially by diseases of late life. Annals of Neurology. 2008; 64:698-706. DOI: 10.1002/ana.21557 [PubMed: 19107993]

Yeung SE, Fischer AL, Dixon RA. Exploring effects of type 2 diabetes on cognitive functioning in older adults. Neuropsychology. 2009; 23:1-9. DOI: 10.1037/a0013849 [PubMed: 19210028]

Zahodne LB, Glymour MM, Sparks C, Bontempo D, Dixon RA, MacDonald SW, Manly JJ. Education does not slow cognitive decline with aging: 12-year evidence from the Victoria Longitudinal Study. Journal of the International Neuropsychological Society. 2011; 17:1039-1046. DOI: 10.1017/S1355617711001044 [PubMed: 21923980]

Zimprich D, Mascherek A. Five views of a secret: Does cognition change during middle adulthood? European Journal of Ageing. 2010; 7:135-146. DOI: 10.1007/s10433-010-0161-5 [PubMed: 28798624] 


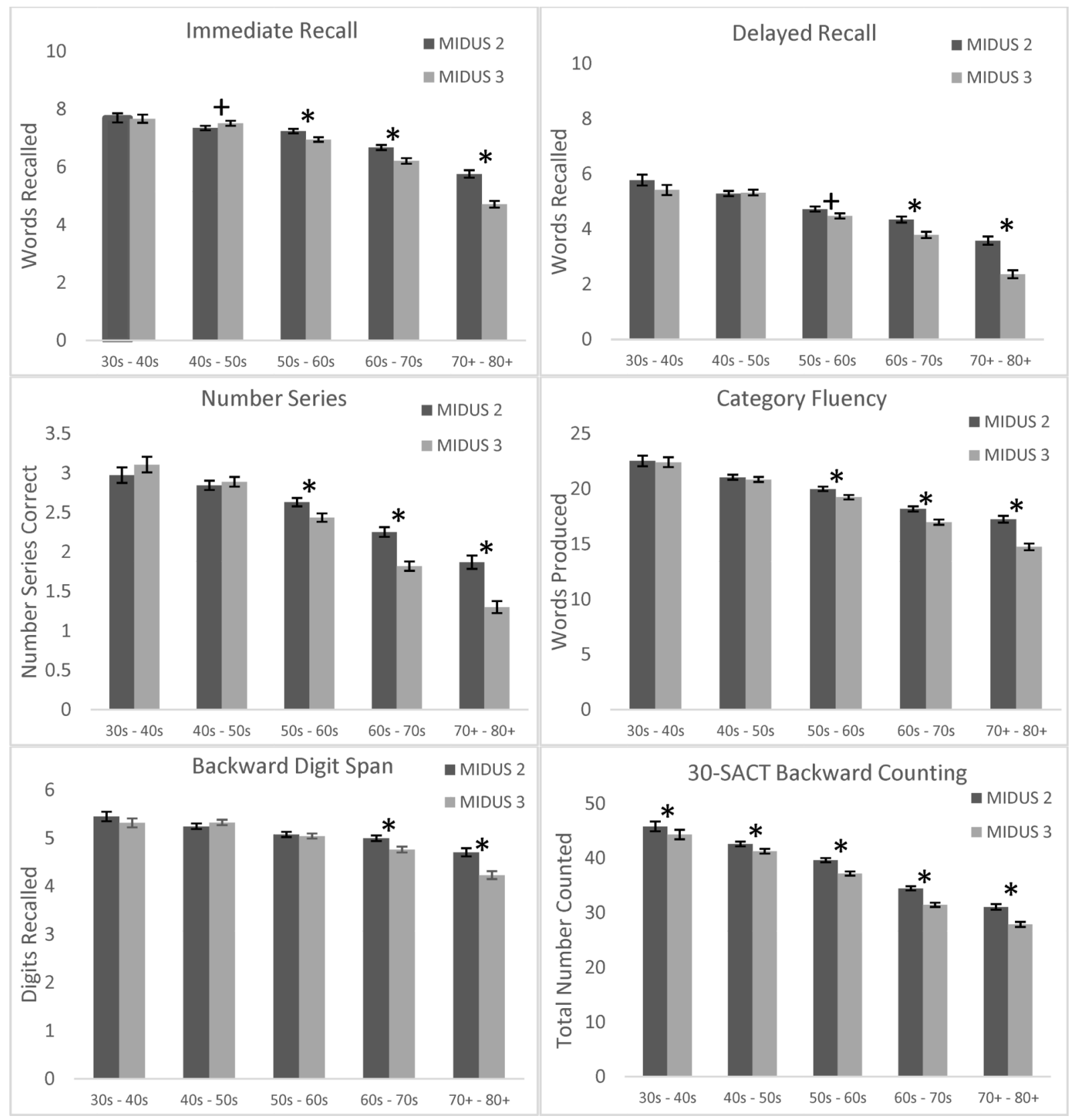

J Int Neuropsychol Soc. Author manuscript; available in PMC 2018 October 04. 


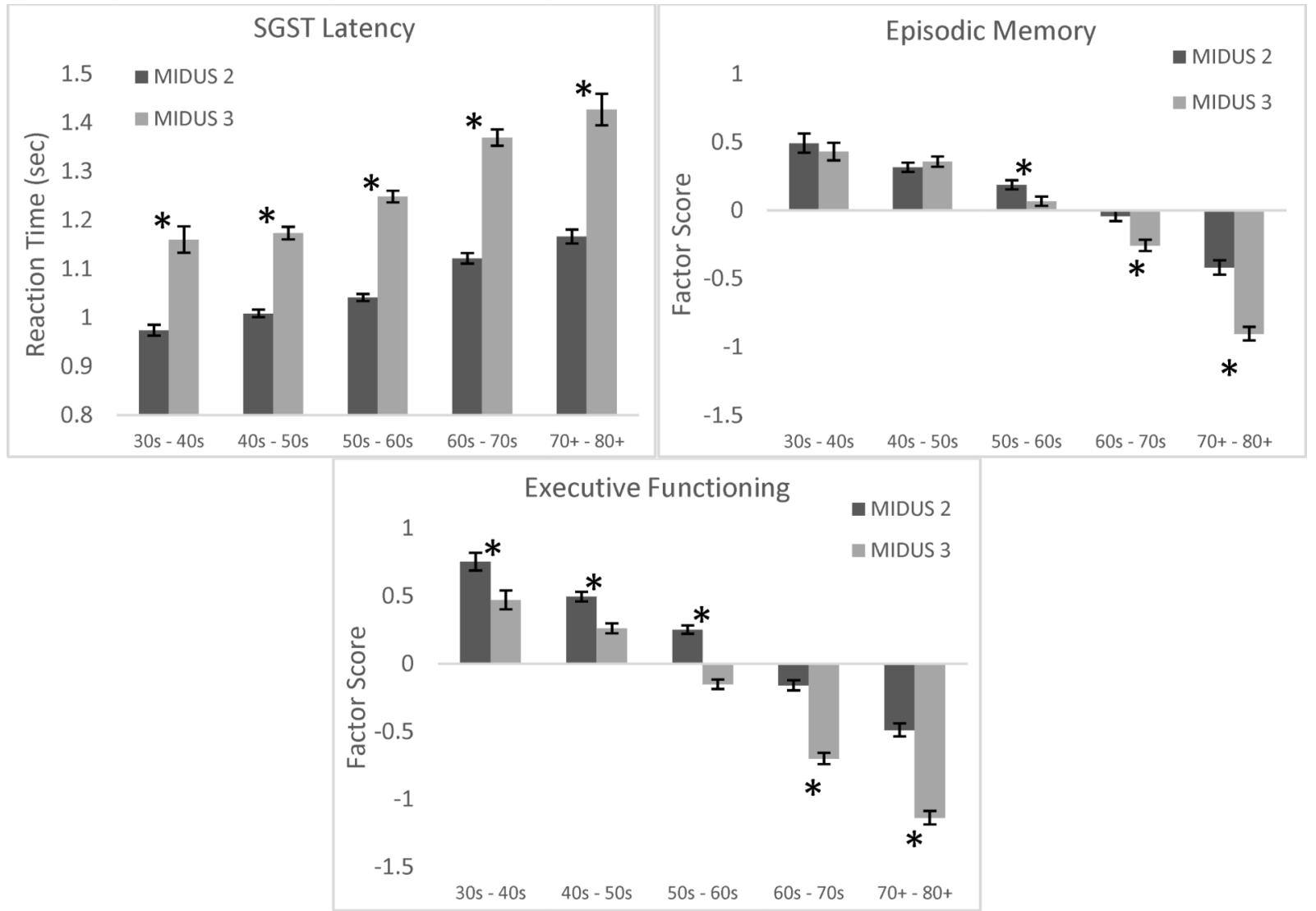

Figure 1.

Mean Subtest and Factor Scores at MIDUS 2 and MIDUS 3 for the Longitudinal Sample by Age Decade at MIDUS 2 (dark bars) and MIDUS 3 (light bars)

Note: * Indicates significant change at $p<.001$, +indicates significant change at $p<.05$

within age groups based on pairwise comparisons from the doubly multivariate analysis with repeated measures (see Table S2). 


\section{Table 1}

Comparison of MIDUS 3 Longitudinal Participants and Dropouts on Demographic Variables, Health, and Cognitive Scores at MIDUS $2(\mathrm{~N}=4,206)$.

\begin{tabular}{|c|c|c|c|c|}
\hline & \multicolumn{2}{|c|}{ Longitudinal } & \multicolumn{2}{|c|}{ Dropout } \\
\hline & Mean (SD) & Range & Mean (SD) & Range \\
\hline Age ${ }^{*}$ & $55.20(11.19)$ & $33-83$ & $57.18(13.77)$ & $28-84$ \\
\hline Sex (Women) & $55.3 \%$ & - & $52.4 \%$ & - \\
\hline Education (years) ${ }^{*}$ & $14.69(2.61)$ & $6-20$ & $13.83(2.57)$ & $6-20$ \\
\hline Race (White) ${ }^{*}$ & $93.1 \%$ & & $90 \%$ & \\
\hline Self-Rated Health ${ }^{*}$ & $3.68(0.93)$ & $1-5$ & $3.34(1.09)$ & $1-5$ \\
\hline Immediate Word List Recall ${ }^{*}$ & $7.00(2.19)$ & $0-15$ & $6.32(2.37)$ & $0-15$ \\
\hline Delayed Word List Recall ${ }^{*}$ & $4.69(2.51)$ & $0-14$ & $4.01(2.73)$ & $0-14$ \\
\hline Number Series $*$ & $2.51(1.50)$ & $0-5$ & $1.92(1.47)$ & $0-5$ \\
\hline Category Fluency ${ }^{*}$ & $19.73(6.02)$ & $1-42$ & $17.36(6.11)$ & $0-42$ \\
\hline Backward Digit Span ${ }^{*}$ & $5.09(1.46)$ & $0-8$ & $4.88(1.57)$ & $0-8$ \\
\hline 30-SACT Backward Counting * & $38.66(11.20)$ & $-2-90$ & $35.15(11.45)$ & $2-100$ \\
\hline SGST Latency ${ }^{*}$ & $1.07(.23)$ & $.61-3.77$ & $1.13(.34)$ & $.22-7.36$ \\
\hline Episodic Memory ${ }^{*}$ & $0.12(.95)$ & $-2.42-3.83$ & $-0.18(1.04)$ & $-3.07-3.63$ \\
\hline Executive Functioning ${ }^{*}$ & $0.17(.95)$ & $-3.28-3.42$ & $-0.25(1.01)$ & $-4.74-2.68$ \\
\hline
\end{tabular}

J Int Neuropsychol Soc. Author manuscript; available in PMC 2018 October 04. 


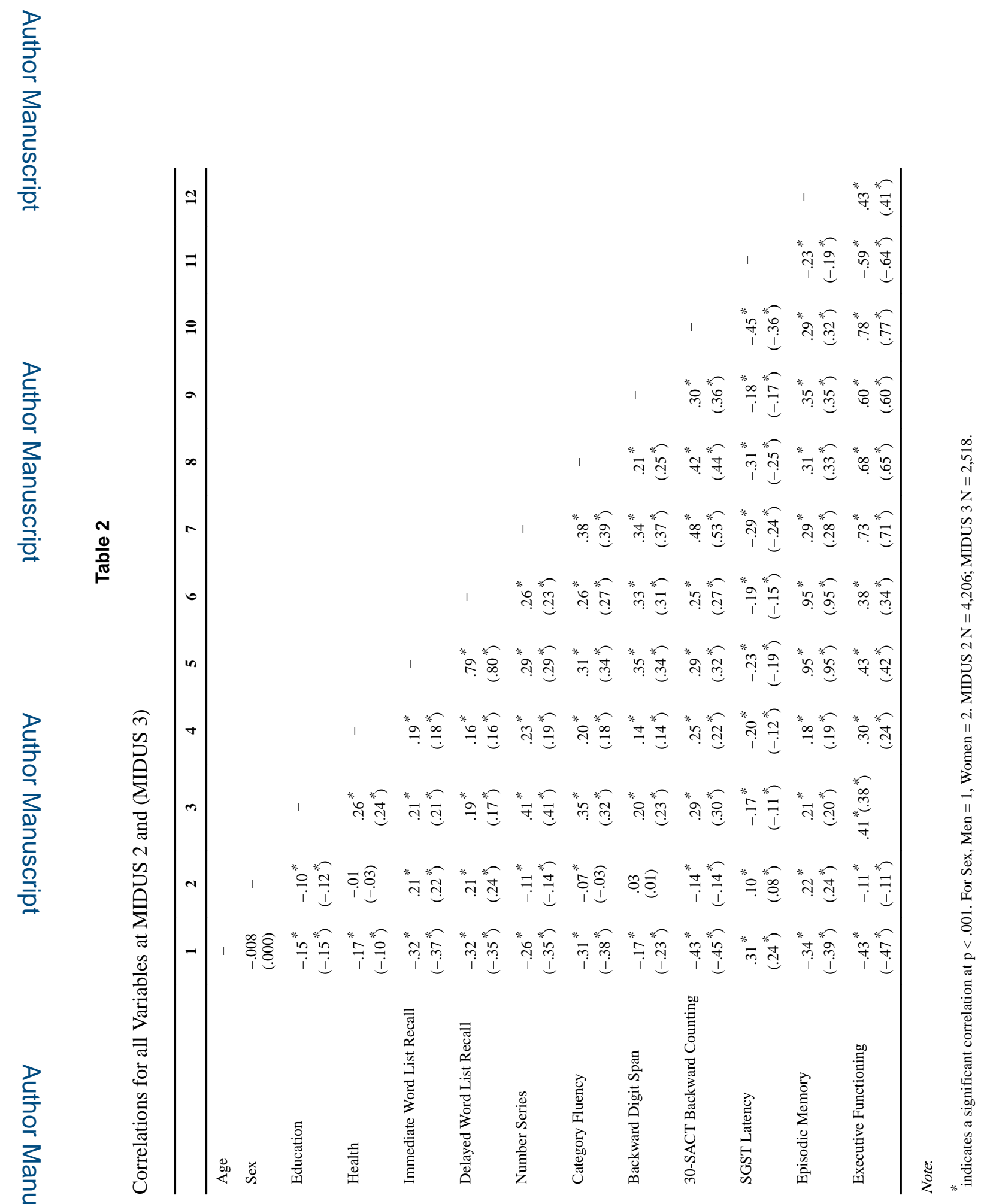


Table 3

Stability Correlations between MIDUS 2 and MIDUS 3 Cognitive Measures $(N=2,516)$

\begin{tabular}{ll}
\hline Cognitive Measure & MIDUS 2 to MIDUS 3 Correlation \\
\hline Immediate Word List Recall & $.48^{*}$ \\
\hline Delayed Word List Recall & $.52^{*}$ \\
\hline Number Series & $.64^{*}$ \\
\hline Category Fluency & $.64^{*}$ \\
\hline Backward Digit Span & $.47^{*}$ \\
\hline 30-SACT Backward Counting & $.85^{*}$ \\
\hline SGST Latency & $.38^{*}$ \\
\hline Episodic Memory & $.54^{*}$ \\
\hline Executive Functioning & $.76^{*}$ \\
\hline Note: & \\
indicates significant correlations at p $<.001$. &
\end{tabular}


Table 5

Parameters from Confirmatory Factor Analysis with Weak Measurement Invariance

\begin{tabular}{|c|c|c|c|c|}
\hline Item or factor & $\begin{array}{c}\text { Episodic Memory } \\
\text { MIDUS } 2\end{array}$ & $\begin{array}{l}\text { Episodic Memory } \\
\text { MIDUS } 3\end{array}$ & $\begin{array}{c}\text { Executive Functioning } \\
\text { MIDUS 2 }\end{array}$ & $\begin{array}{c}\text { Executive Functioning } \\
\text { MIDUS } 3\end{array}$ \\
\hline & \multicolumn{4}{|c|}{ Standardized factor loadings } \\
\hline Immediate Word List Recall & 0.94 & 0.95 & & \\
\hline Delayed Word List Recall & 0.84 & 0.85 & & \\
\hline Number Series & & & 0.56 & 0.50 \\
\hline Category Fluency & & & 0.57 & 0.60 \\
\hline Backward Digit Span & & & 0.44 & 0.48 \\
\hline 30-Sact Backward Counting & & & 0.75 & 0.77 \\
\hline SGST Latency & & & 0.59 & 0.39 \\
\hline
\end{tabular}

Episodic Memory MIDUS 2

$--$

Factor correlations

Episodic Memory MIDUS 3

0.62

Executive Functioning MIDUS 2

0.62

Executive Functioning MIDUS 3

0.49

0.46

0.53

0.94

Note. Parameters are all statistically significant at $\mathrm{p}<.001$ 


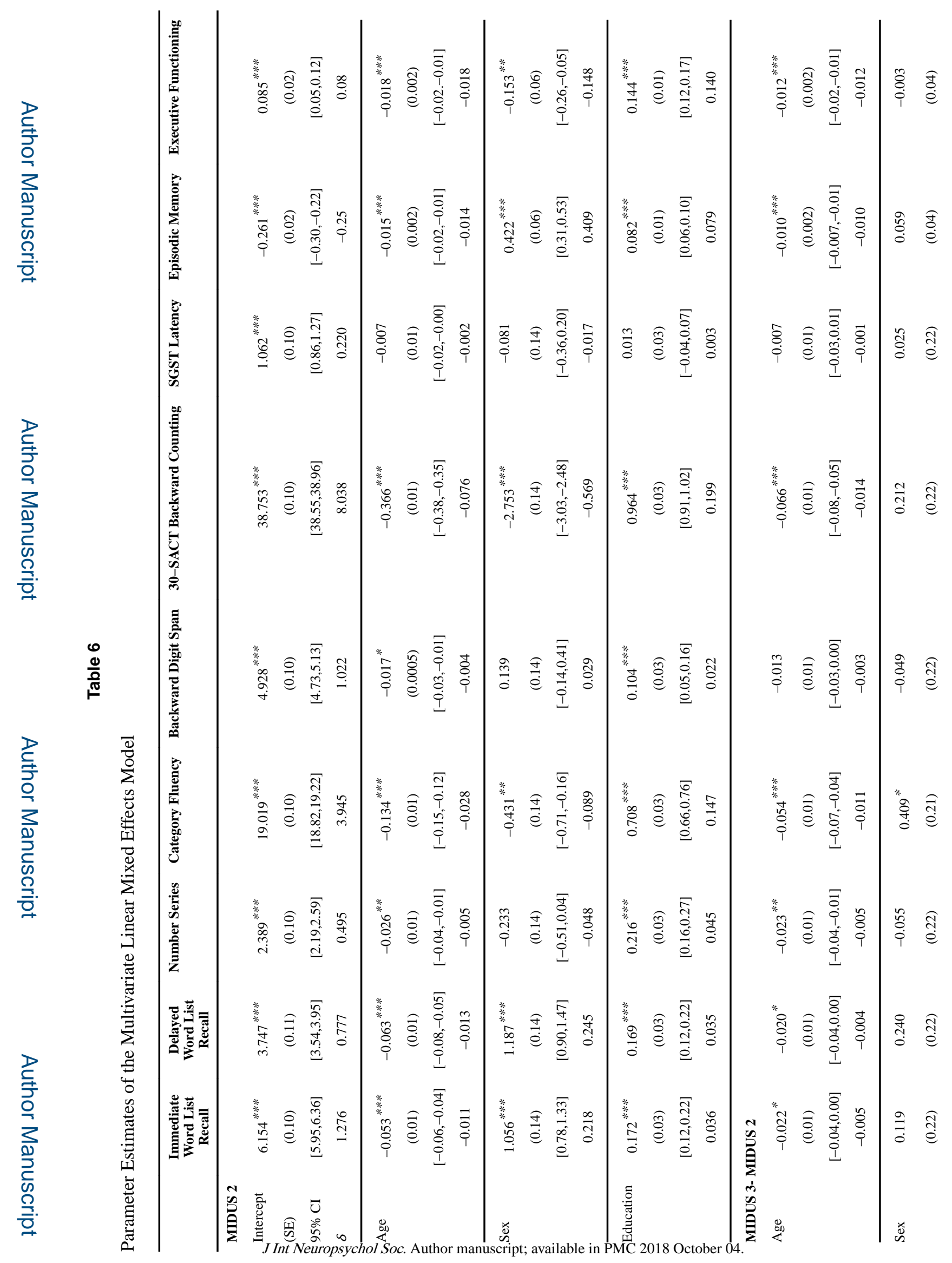


Hughes et al.

Page 29

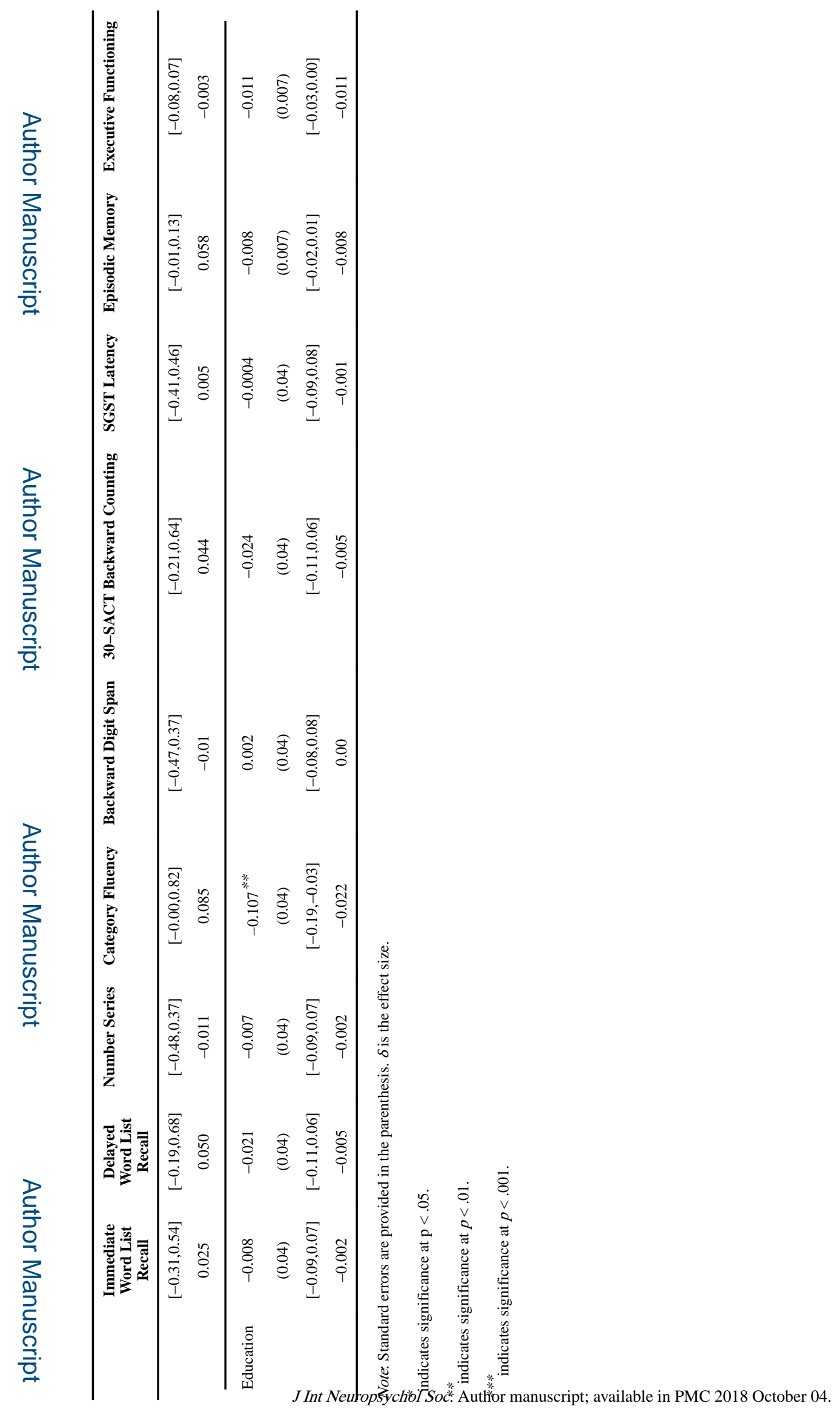




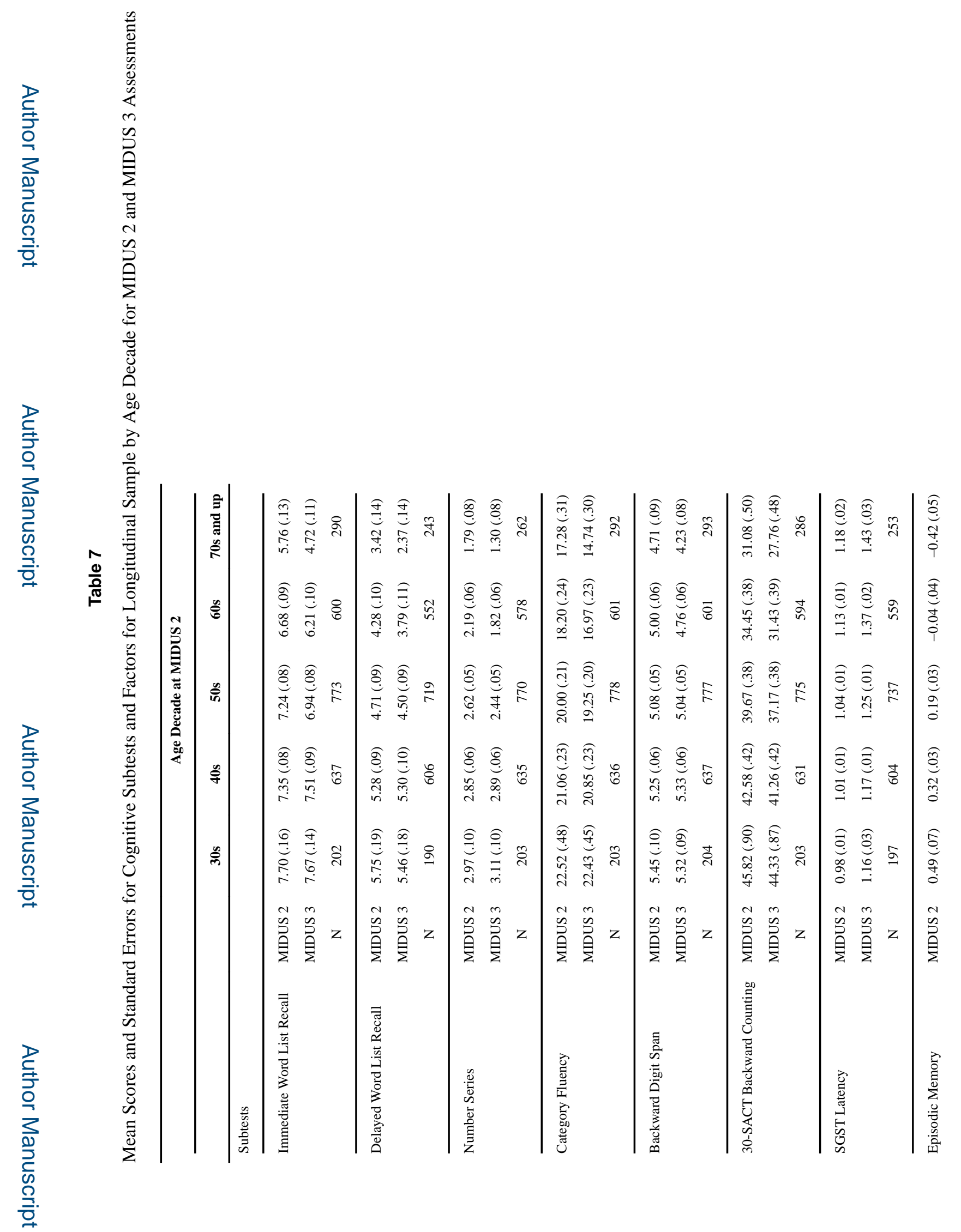




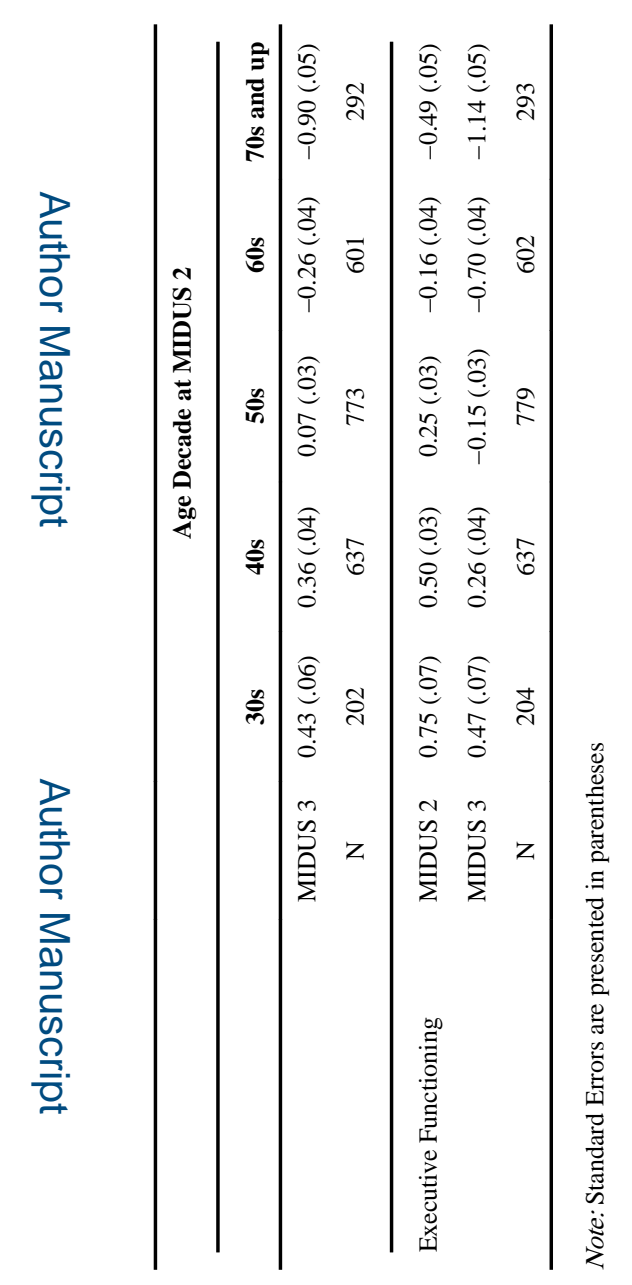

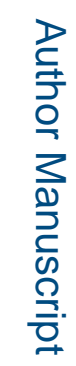

로을 